\title{
DISTRIBUIÇÃO DE METAIS PESADOS (COBRE, ZINCO E CHUMBO) EM ÁREAS RURAIS DO GRANDE RIO DE JANEIRO*.
}

\author{
ROBERT GREENWOOD**
}

\begin{abstract}
As part of a research program in environmental geochemistry, three rural areas close to Rio de Janeiro were sampled for traces of lead, copper and zinc. By atomic absorption analysis, seventeen samples of granitic rocks gave averages of 17,17 and $51 \mathrm{ppm}$ for $\mathrm{Pb}, \mathrm{Cu}$ and $\mathrm{Zn}$, respectively; 28 samples of residual soil gave 28 , 11 and $28 \mathrm{ppm}$; thirty samples of fluvial sediments 25,14 and $31 \mathrm{ppm}$; and 26 samples of lagoonal sediments 32,26 and $48 \mathrm{ppm}$.

These values are within the expected range for areas with little or no contamination, and can be used for comparison with neighboring areas which have undergone heavy metal pollution. Comparisons between rocks soils and fluvial sediments show increases in $\mathrm{Pb}$ and decreases in $\mathrm{Cu}$ and $\mathrm{Zn}$ related to their relative solubilities during intense chemical weathering. The moderate increase in all three metals in lagoonal sediments is related to their affinity for clays, and possibly for organic material.
\end{abstract}

OBJETIVOS A geoquímica regional dos metaistraço na região do Grande Rio de Janeiro constitui uma das linhas de pesquisa ora em desenvolvimento no Programa em Geoquímica da Universidade Federal Fluminense. Pretende-se estudar, por comparação de áreas, a distribuição desses metais-traço em diversos ambientes geológicos e geográficos, a fim de distinguir os teores naturais desses metais e a fração proveniente da contaminação urbana e industrial.

A contaminação por metais pesados, especialmente em lagoas e baías, tem sido objeto de estudos no exterior (Helz, 1976; Nriagu, 1979; Rickert, 1976; e Goldberg, 1978) e começa agora no Brasil a atrair a atenção da comunidade científica no sentido de se obterem dados básicos para o desenvolvimento racional do país.

A fase inicial do programa objetivou o levantamento geoquímico dos metais pesados (chumbo, cobre e zinco) em três áreas restritas, ainda pouco afetadas pelo desenvolvimento urbano-industrial, que deverão servir como testemunhos do ambiente natural da região fornecendo o nível de background desses metais.

\section{DISTRIBUIÇÃO DO CHUMBO, DO COBRE E DO ZINCO ENTRE FASES MINERALÓGICAS Nas} rochas e nos sedimentos comuns, os elementos chumbo, cobre e zinco não formam fases mineralógicas próprias, porém se distribuem em traços nas estruturas cristalinas dos minerais silicatados, segundo as propriedades cristaloquímicas, carga iônica, raio iônico e eletronegatividade. Excepcionalmente, em condiçð̃es subaquáticas e bastante redutoras, a atividade microbiana anaeróbica produz traços de sulfetos $-\mathrm{PbS}, \mathrm{Cu}_{2} \mathrm{~S}, \mathrm{CuFeS}_{2}$ ou $\mathrm{ZnS}$ (Greenwood, 1968).

$\mathrm{O}$ íon $\mathrm{Pb}^{2+}$ encontra-se nas rochas cristalinas, especialmente nas graníticas, substituindo o ín $\mathrm{K}^{+} \mathrm{e}$ o $\mathrm{Ca}^{2+}$ nos feldspatos. Nos solos e sedimentos, o íon $\mathrm{Pb}^{2+}$ fixa-se nas argilas, por absorção ou por troca iôni$\mathrm{ca}$, encontrando-se incluído também nas micelas coloidais ou precipitados de ferro e manganês (Lee, 1975).
Os elementos zinco e cobre ocorrem nas rochas cristalinas, nos silicatos máficos (anfibólios, micas e piroxênios) substituindo o ferro em coordenação octaédri$\mathrm{ca}-\mathrm{a}$ preferência do cobre para rochas ígneas máficas é bastante significativa (Krauskopf, 1972 - Tab. 20-5). Pelo intemperismo, o zinco e o cobre se solubilizam e, eventualmente, se associam com os minerais argilosos $\mathrm{e}$ os hidróxidos de ferro e manganês, por absorção ou por troca iônica.

Valores típicos para teores desses elementos em vários ambientes geológicos aparecem na Tab. 1, onde a linha 5 mostra a concentração dos metais pesados na fração fina argilosa, dos sedimentos fluviais.

Tabela 1-Abundâncias típicas de chumbo, cobre e zinco em ambientes geológicos (em ppm)

\begin{tabular}{l|c|c|r}
\hline \multirow{2}{*}{ Amostras } & \multicolumn{3}{|c}{ Elementos } \\
\cline { 2 - 4 } & $\mathrm{Pb}$ & $\mathrm{Cu}$ & $\mathrm{Zn}$ \\
\hline 1. Crosta & 13 & 55 & 70 \\
2. Granodiorito & 20 & 20 & 50 \\
3. Folhelho & 20 & 57 & 80 \\
4. Sed, fluviais & 22 & 10 & 110 \\
5. Sed. fluviais & 55 & 20 & 120 \\
\hline
\end{tabular}

1. Média na crosta terrestre - Krauskopf, (1972), Apêndice III.

2. Média das rochas ígneas, granodioríticas - modificados os valores atribuídos ao granito por Krauskopf, K.B., Apêndice III.

3. Média de folhelhos - Krauskopf, (1972)

4 e 5 . Sedimentos nas cabeceiras do Rio Willamette (média de duas localidades): Rickert (1976)

4 - Topo material $<2 \mathrm{~mm}$

5 - Material $<20$ mícrons

* Financiado pela Universidade Federal Fluminense e pelo CNPq

** Programa de Geoquímica da Universidade Federal Fluminense, Niterói, RJ 
AREAS ESTUDADAS Selecionaram-se as três áreas por ser bacias fluviais de extensão restrita (12 a $16 \mathrm{~km}^{2}$ ), típicas das vizinhanças do Rio de Janeiro, mas ainda pouco modificadas pelas atividades urbanas ou industriais. Descreve-se a seguir cada uma dessas áreas:

\section{BACIA DO CÓRREGO DO SERTÃO (MAGE)}

A bacia situa-se a sudeste da cidade de Santo Aleixo, no município de Magé (RJ), ao sopé da Serra dos Órgãos e a nordeste da Baía de Guanabara (Fig. 1). O Córrego do Sertão nasce como riacho em uma altitude de $350 \mathrm{~m}$ e corre $7 \mathrm{~km}$ na direção sudoeste, tendo a maioria de seu curso num vale situado entre 50 e $15 \mathrm{~m}$ acima do nível da baía. Depois de associar-se a vários afluentes menores, o córrego liga-se ao Rio Roncador, que passa pela zona urbana de Magé, desembocando na Baía de Guanabara.

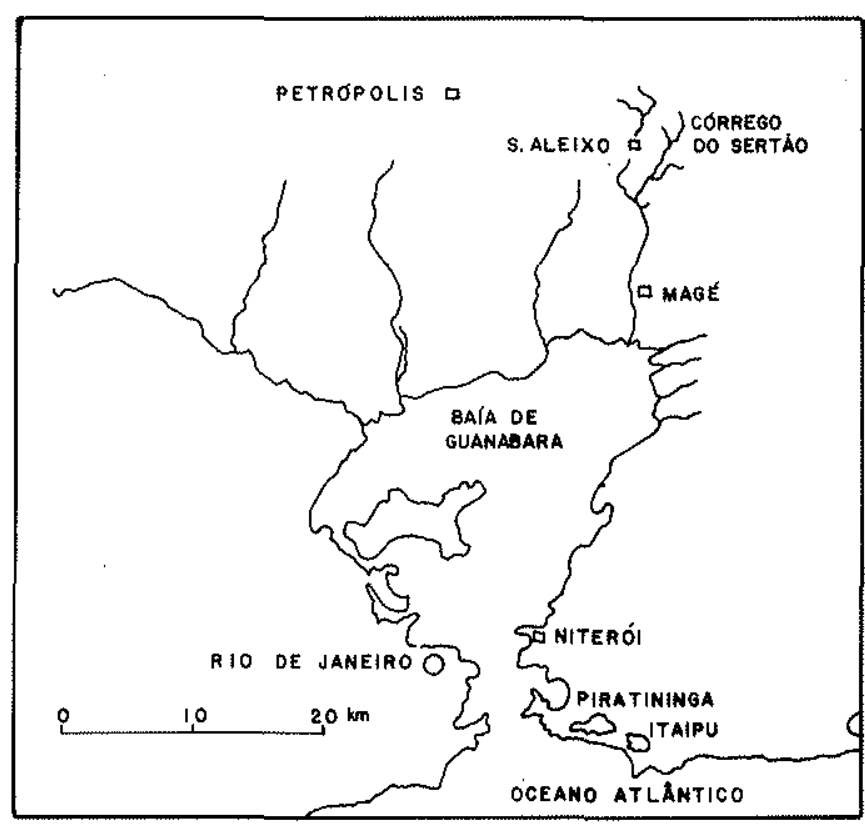

Figura 1 - Localização das áreas estudadas região do Rio de Janeiro

A topografia acidentada da bacia é erodida em rochas pré-cambrianas, metamórficas, incluindo migmatitos graníticos e vários tipos de gnaisses. Diques máficos ocorrem, porém em proporçð̃es insignificantes para a geoquímica regional.

Há espessos solos residuais nas encostas mais baixas e sedimentos fluviais, argilo-arenosos, nos vales de córrego e de seus afluentes. Os morros ainda conservam a floresta tropical enquanto o vale principal, desmatado já há vários anos, suporta alguma atividade agropastoril. Ao longo do texto, esta área será chamada de "Magé".

\section{BACIA DA LAGOA DE PIRATININGA}

A Lagoa de Piratininga, no município de Niterói, é a primeira na série das lagunas costeiras, que se estende de Niterói até Cabo Frio (Fig. 1). E uma laguna rasa, prati- camente isolada do oceano por sua restinga de areia e a leste ligada à Lagoa de Itaipu por um canal artificial. Devido a esta conexão, o abaixamento artificial da Lagoa de Itaipu $(1978 / 1979)$ tem contribuído para as baixas do nível da Lagoa de Piratininga. A salinidade da laguna é variável, ficando em torno de $5 \%$, ou seja, $14 \%$ da salinidade do oceano.

A nordeste, a bacia fluvial que alimenta a lagoa junta a drenagem numa extensão de $12 \mathrm{~km}^{2}$, formando o pequeno Rio Jacaré, que desemboca na margem panta nosa da lagoa. A topografia acidentada nos dois lados do vale do Jacaré inclui morros íngremes acima de $200 \mathrm{~m}$ de altura. A rocha preponderante é o gnaisse típico de Niterói (Lamego, 1945) de composição granítica, e com cristais de feldspato de vários centímetros de espessura. Diques máficos são esparsos. Nas encostas e baixadas desenvolvem-se espessos solos residuais e, no estreito vale, encontram-se sedimentos fluviais, principalmente arenosos, com camadas argilosas.

$O$ vale do Jacaré sustenta uma pequena populaçăo rural e alguma atividade hortigranjeira. Na orla norte da laguna, existe uma malha de ruas inacabadas, testemunhos da remoção dos solos e das drenagens originais. Entretanto, a construção urbana ali ainda encontra-se em sua fase inicial tendo-se acelerado mais a partir de 1978, principalmente na restinga, situada ao sul da lagoa. No texto a seguir, refere-se a esta área como "Piratininga".

\section{BACIA DA LAGOA DE ITAIPU}

A scgunda da série de lagunas costeiras é Itaipu, situada a sudeste do município de Niterói, ligando-se à Lagoa de Piratininga pelo canal já mencionado e que se comunica com o oceano por uma abertura artificial, a sudeste, recentemente alargada em razão do que só fez aumentar a tendência de a laguna de ser rasa.

A salinidade de Lagoa de Itaipu, na época da coleta, foi determinada em $7 \% 0$, valor que corresponde a um quinto da salinidade do mar e que está sujeito a oscilaçð̃es de conformidade com as estaçðes e as marés.

As mudanças nesta laguna, incluindo loteamentos, aterros e a construção de marinas no lado oeste $(1978 / 1979)$ bem como a crescente urbanização na baixada a norte, fazem dessa bacia um laboratório para quem busca estudar modificaçőes na ecologia costeira ou na geoquímica ambiental.

A bacia fluvial, que alimenta a laguna pelo pequeno Rio João Mendes, tem uma área de, aproximadamente, $15 \mathrm{~km}^{2}$. Na maioria de sua extensão, é uma baixada ligeiramente ondulada, com colinas de até $25 \mathrm{~m}$ de altura, e limitada a oeste e a leste por morros e encostas íngremes de até 200-300 $\mathrm{m}$ de altitude.

As rochas da área são gnaisses pré-cambrianos de várias litologias predominando aquelas de composição granítica e com grandes cristais de feldspato. $\mathrm{Na}$ baixa$\mathrm{da}$, espessos solos residuais cobrem as colinas suaves, entre as quais os processos fluviais têm depositado camadas de sedimentos arenosos e argilosos.

As restingas e dunas de areia do lado oceânico contrastam com as lamas argilosas das partes internas da laguna, produtos de transporte fluvial provenientes do norte. No texto, refere-se a esta área como "Itaipu". 
METOdOLOGIA DE CAMPO Com o auxílio de mapas topográficos na escala de 1:50 000 do IBGE e de fotografias aéreas, estabeleceram-se os pontos apropriados para o reconhecimento geológico e a amostragem, sendo que na área de Magé, utilizou-se o mapeamento geológico em fase de publicação do Departamento de Recursos Minerais do Estado do Rio de Janeiro.

Em cada área, selecionaram-se para análise amostras típicas de três ambientes geológicos: rochas cristalinas, solos residuais delas derivados e sedimentos fluviais. No caso de Piratininga e Itaipu, escolheu-se mais um ambiente, aquele dos sedimentos argilosos à margem da lagoa.

ROCHAS CRISTALINAS Procurou-se fazer as amostragens das rochas cristalinas na proporção em que as várias litologias se encontram na área. Por exemplo, o diabásio, amostrado e analisado, forneceu $90 \mathrm{ppm}$ de $\mathrm{Cu}$, porém os resultados de suas análises não foram incluídos nas médias uma vez que o diabásio representa menos de $0,1 \%$ das rochas em cada área. Em cada afloramento escolhido, selecionou-se uma variedade de pedaços, suficientes para compor uma amostra de $1 \mathrm{~kg}$.

SOLOS RESIDUAIS As amostras de solo foram coletadas principalmente em cortes de estrada em que a relação com a rocha-mãe torna-se evidente. Recolheu-se uma quantidade aproximada de $1 \mathrm{~kg}$. Mesmo que a estratificação de solos seja pouco evidente, as amostras correspondem, na medida do possivel, "ao horizonte " $\mathrm{B}$ ", onde ocorre acúmulo de alumínio e do ferro pelo intemperismo.

SEDIMENTOS FLUVIAIS Como representantes do ciclo de sedimentação mais recente, esses materiais ficam expostos na margem dos principais cursos de água da região. Procurou-se estudar os sedimentos com um maior teor' de argila por apresentarem uma tendência maior de fixar os metais pesados. Coletou-se, aproximadamente, $1 \mathrm{~kg}$ de cada amostra em saco plástico. No caso de material saturado ao nível da água, introduziu-se um tubo de plástico PVC, rígido, de $3 \mathrm{~cm}$ de diâmetro, até uma profundidade de $20-30 \mathrm{~cm}$, para a coleta do material.

\section{SEDIMENTOS DE LAGUNAS Coletaram-se sedi-} mentos lacustres em Itaipu em três pontos às margens da laguna (nâo incluindo a restinga). Em Piratininga, a amostragem foi feita próximo à desembocadura do Rio Jacaré. Por serem sedimentos saturados e finos, variando de argila a areia fina, recolheram-se testemunhas com o tubo plástico de $\mathrm{PVC}$, de $20 \mathrm{~cm}$ de comprimento, aproximadamente.

Em Itaipu, a parte superficial da amostra foi analisada separadamente da parte inferior, porém as análises não acusaram diferenças significativas.

METODOLOGIA DE LABORATÓRIO Analisouse um total de 104 amostras em relação ao chumbo, ao cobre e ao zinco, sendo que 27 amostras (Magé) foram analisadas também para o ferro, buscando-se avaliar possíveis correlaçóes entre hidróxidos de ferro e outros metais pesados (Lee, 1975).

Inicialmente, a granulometria das rochas cristalinas foi reduzida a menos de $1 \mathrm{~cm}$ por um britador de mandíbulas. Em seguida, tomou-se uma porção de $50 \mathrm{~g}$ de cada rocha para quarteamento e moagem, tendo-se utilizado nesta última operação um moinho de cilindros, do Centro de Tecnologia Mineral (Cetem/CPRM$\mathrm{RJ}$ ). Os solos residuais foram pulverizados e, após secagem, moagem e homogeneização, tirou-se $0,4 \mathrm{~g}$ para análise. As amostras foram dissolvidas, cada uma, com $5 \mathrm{ml}$ de ácido nítrico concentrado (P.A.), a quente, durante duas horas de digestão a uma temperatura de $90^{\circ} \mathrm{C}$ seguida pela filtração e diluição até $40 \mathrm{ml}$. Digestões oụ fusões com pirossulfato de potássio (Ward, 1963 , p. 19) resultaram em soluçôes concentradas em sulfato que prejudicaram a técnica de análise por absorção atômica. Todas as análises foram realizadas por espectrofotometria de absorção atômica, tendo-se, para tanto, utilizado o modelo A-3400 da Baird Atomic.

EXATIDÃO DO MÉTODO Para testar a exatidão dos resultados, analisaram-se, em paralelo, duas rochas-padrão do U.S. Geological Survey, selecionadias por ser de composiçóes semelhantes a nosso material coletado: uma o GSP-1, um granodiorito, de composição análoga às rochas cristalinas e outra o MAG-1, Marine Mud, uma lama marinha com composição semelhante aos sedimentos de laguna (Flanagan, 1976).

Com apenas uma exceção, as análises para esses padroes forneceram resultados entre $65 \%$ e $90 \%$ das médias dos teores citados por Flanagan, mostrando que a digestão em ácido nítrico foi satisfatória, excetuandose o teor de chumbo na amostra-padrão MAG-1, para o qual se obteve uma média de $35 \mathrm{ppm}$, ao passo que Flanagan cita $20,4 \mathrm{ppm}$, obtida por espectrografia de emissão.

Para os fins deste levantamento inicial de metaistraço a exatidão atingida pode ser considerada razoável.

SENSIBILIDADE E PRECISÃO Uma das maneiras de determinar a sensibilidade, em espectrofotometria de absorção atômica, é estipulá-la como sendo a concentração que corresponde a uma absorbância de $1 \%$. As sensibilidades obtidas para as amostras, levando-se em conta o fator 100 entre a solução e a amostra, são as seguintes: chumbo, 2,0 ppm; cobre, 0,9 ppm; e zinco, 0,6 ppm.

Considerações a respeito da precisão dividem-se em duas etapas: a reprodutibilidade do teor medido na mesma solução (precisão da análise) e a reprodutibilidade em duas digestôes do mesmo material (precisão da abertura). Para as amostras com teores baixos, a diferença entre duas análises da mesma solução foi da ordem de $20 \%$ para o chumbo e de $10 \%$ para cobre e zinco. Pela análise de dezoito amostras com digestão em duplicata, entretanto, as diferenças podem chegar ao dobro das citadas. Este problema é geral na geoquímica e foi considerado por Nicholls (1971), entre outros pesquisadores. Evidentemente, há necessidade de se padronizar melhor - procedímento da homogeneização e da abertura química das amostras.

RESULTADOS A Tab. 2 mostra os teores médios de chumbo, cobre e zinco encontrados nas três áreas estudadas, para cada ambiente geológico, sendo que, na bacia do Córrego do Sertão (Magé), não há sedimentos de laguna. A tabela indica também o número de amos. tras somadas na média de cada categoria bem como o 
Tabela 2 - Resultados das análises químicas

\begin{tabular}{|c|c|c|c|c|c|c|c|c|c|c|c|c|}
\hline \multirow{2}{*}{$\ldots$} & \multicolumn{3}{|c|}{ Rochas } & \multicolumn{3}{|c|}{ Solos } & \multicolumn{3}{|c|}{$\begin{array}{l}\text { Sedimentos } \\
\text { fluviais }\end{array}$} & \multicolumn{3}{|c|}{$\begin{array}{l}\text { Sedimento de } \\
\text { lagoa }\end{array}$} \\
\hline & $\bar{x}$ & $n$ & $s$ & $\bar{x}$ & $n$ & $s$ & $\bar{x}$ & $n$ & $s$ & $\bar{x}$ & $n$ & $s$ \\
\hline \multicolumn{13}{|l|}{ Chumbo } \\
\hline Magé & 14 & 4 & 2 & 33 & 9 & 8 & 28 & 12 & 8 & & & \\
\hline Piratininga & 18 & 5 & 3 & 29 & 11 & 9 & 28 & 10 & 7 & 46 & 10 & 15 \\
\hline Itaipu & 18 & 8 & 7 & 20 & .8 & 8 & 17 & 8 & 8 & 23 & 16 & 12 \\
\hline Média Regional & 17 & & & 28 & & & 25 & & & 32 & & \\
\hline \multicolumn{13}{|l|}{ Cobre } \\
\hline Magé & 11 & 4 & 9 & 8 & 9 & 4 & 7 & 12 & 2 & & & \\
\hline Piratininga & 16 & 5 & 3 & 12 & 11 & 2 & 17 & 10 & 9 & 20 & 10 & 4 \\
\hline Itaipu & 21 & 8 & 4 & 14 & 8 & 6 & 18 & 8 & 5 & 30 & 16 & 9 \\
\hline Média regional & 17 & & & 11 & & & 14 & & & 26 & & \\
\hline \multicolumn{13}{|l|}{ Zinco } \\
\hline Magé & 47 & 4 & 8 & 21 & 9 & 14 & 46 & 12 & 24 & & & \\
\hline Piratininga & 40 & 5 & 13 & 18 & 11 & 17 & 26 & 10 & 13 & 50 & 10 & 23 \\
\hline Itaipu & 60 & 8 & 22 & 50 & 8 & 29 & 14 & 8 & 13 & 46 & 16 & 21 \\
\hline Média regional & 51 & & & 28 & & & 31 & & & 48 & & \\
\hline \multicolumn{13}{|l|}{ Ferro $(\%)$} \\
\hline Magé & 1,7 & 4 & 0,6 & 2,3 & 9 & 0,4 & 1,5 & 12 & 0,6 & & & \\
\hline Piratininga & 1,6 & 5 & 0,13 & 1,5 & 10 & 0,24 & 1,4 & 10 & 0,25 & 1,6 & 10 & 0,47 \\
\hline
\end{tabular}

$\bar{x}=$ Média das análises, em ppm (Fe, em \%)

$n=$ Número de amostras incluídas na média

$s=$ Desvio-padrão

desvio-padrão. Para a área Magé, consideram-se as médias das análises para o ferro também.

As perspectivas médias regionais para chumbo, cobre e zinco nos quatro ambientes geológicos são as seguintes: rochas cristalinas 17,17 e 51 ppm (dezessete amostras); solos residuais 28,11 e 28 ppm (28 amostras); sedimentos fluviais 25,14 e 31 ppm (trinta amostras); e sedimentos de laguna 32,26 e 48 ppm (26 amostras) (Tab. 2).

DISCUSSÕES E CONCLUSÕES Para avaliar os dados da Tab. 2, lançaram-se em gráfico os resultados na Fig. 2. Pode-se observar que os teores de metaistraço se situam dentro ou próximo da faixa normal para tais ambientes geológicos (Tab. 1), o que é de esperar para regiões rurais e ainda pouco contaminadas. $O$ estudo permitirá uma comparação com ambientes vizinhos contaminados, como a Baía de Guanabara, bem como para avaliar futuras contaminaçôes nas áreas estudadas.

Outros geoquímicos (Lee, 1975) observam uma correlação entre a fixação de metais pesados em solos e sedimentos, e seu conteúdo de hidróxidos de ferro ou de manganês; os resultados do presente trabalho, porém, não permitiram tal correlação com ferro na área de Magé.

Para tratar do comportamento geoquímico dos metais pesados, é preferível considerá-los separadamente.

CHUMBO Pela pouca solubilidade do $\mathrm{Pb}^{2+}$ é de esperar que ele sofra um enriquecimento residual durante os processos de intemperismo, erosão e sedimentação, devido à perda dos elementos mais solúveis das rochas. Essa tendência evidencia-se, de fato, nas áreas de Magé e Piratininga. $\mathrm{O}$ enriquecimento de chumbo nos sedi- mentos de laguna, em Piratininga, pode ser atribuído ou à absorção deste elemento pelas argilas carregadas pelo Rio Jacaré ou à poluição atmosférica, ou ainda, a essas duas causas combinadas. Estudos feitos em zonas urbanas dos EUA (Cannon, 1976) mostram teores de chumbo da ordem de $2 \mathrm{mg} / \mathrm{m}^{3}$ em comparação com o teor de $0,3 \mathrm{mg} / \mathrm{m}^{3}$ nos subúrbios. Acredita-se que o aumento seja resultante da queima de gasolina.

É estranho, pois, que a área de Itaipu não tenha mostrado enriquecimento paralelo de Piratininga, visto que os materiais e os processos geológicos são semelhantes nas duas áreas.

COBRE Da rocha cristalina para o solo residual, o cobre mostrou um decréscimo nas três áreas, resultado de sua solubilidade relativamente alta uma vez liberado pelo intemperismo em clima úmido quente. Nos sedimentos fluviais de Magé, o teor de cobre diminui ainda mais, porém nas duas áreas de lagoas costeiras seu teor nos sedimentos iguala ao da rocha cristalina e aumenta consideravelmente nos sedimentos da lagoa. Provavelmente, este comportamento deve-se ao fato de o $\mathrm{Cu}^{+2}$ dissolvido estar absorvido nas argilas dos sedimentos.

ZINCO O zinco, elemento mais abundante na crosta que o chumbo ou o cobre (Tab. 1), segue o comportamento deste último mas com variaçð̄es locais mais amplas. Como elemento relativamente solúvel por intemperismos, o teor do zinco diminui das rochas cristalinas para os solos e sedimentos fluviais; entretanto os solos de Itaipu e os sedimentos fluviais de Magé forneceram teores médios bastante altos para o zinco (Tab. 2, Fig. 2).

Tendo em vista os altos valores do desvio-padrão associados a esses dois grupos de análises, merecem aque- 

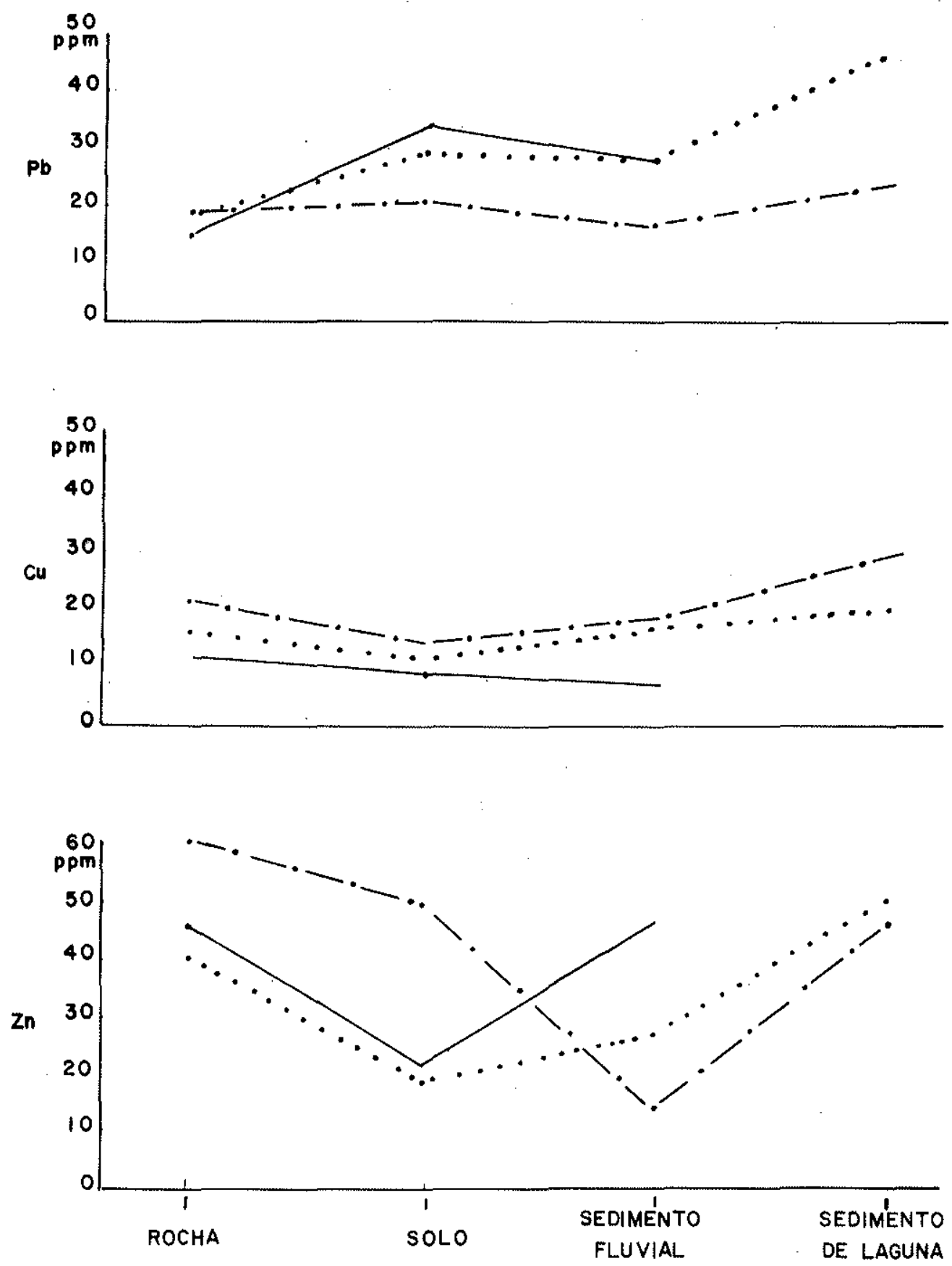

Figura 2 - Teores médios de chumbo, cobre e zinco na região estudada.

Legenda: Magé, Piratininga e Itaipu

les ambientes uma amostragem e análise mais amplas para o zinco. Como no caso do cobre, os teores de zinco nos sedimentos de lagoa chegaram até o nível encontrado nas rochas cristalinas, provavelmente por absorção nas argilas.

Nota-se que, nas cabeceiras do Rio Willamette (EUA), área também pouco poluída, o teor de zinco nos sedimentos mais finos atinge um valor bastante alto (Fig. 1) de Rickert, 1976).

A tendência com que os metais pesados aumentam seus teores nos sedimentos de lagoa confirma a conclusão de que sedimentos lacustres ou estuarinos agem como sinks ou acumuladores de metais pesados. Assim, uma vez acumulado um volume de sedimento enriqueci- 
do em metais pesados pelầ poluição dos rios, o simples embargo das fontes de poluição năo resolve o problema das águas contaminadas. Isso porque, pelas reaçôes solubilizantes, inclusive as orgânicas, o pacote de sedimentos devolverá às águas, durante muitos anos, sua carga de metais pesados (DeGroot e Allersma, 1975; e Bothner, 1980).

O presente trabalho evidencia a viabilidade do estudo da distribuição de metais pesados em ambientes su- perficiais do Estado do Rio de Janeiro, devendo, numa segunda fase, ser estendido a outras áreas mais poluídas da região e incluindo a análise de metais de importância ambiental, como cádmio, niquel, cromo e mercúrio. $\mathbf{P a}$ ra o chumbo e o cádmio, sugere-se a extração pelo uso de complexantes orgânicos, tais como ditizona, APDC, etc. Seria interessante distinguir nos futuros trabalhos a distribuição dos metais pesados pelas várias fraçðes de cada amostra.

\section{BIBLIOGRAFIA}

BOTHNER, M.H. - 1980 - Rate of mercury loss from contaminated estuarines sediments, Geoch. Cosmoch. Acta 44:273-85.

CANNON, H.L. - 1976 - "Lead in the atmosphere, "Lead in the environment" In: U.S. Geol. Survey, Prof, Paper no 957, pp. 73-79.

DeGROOT, A.J. e ALLERSMA, E - - 1975 - "Field observation on the transport of heavy metals in sediments." In: Krenkel, P.A. (ed.), "Heavy Metals in the Aquatic Environment"., Pergamon Press, pp. 85-95.

FLANAGAN, F.J. - 1976 - Descriptions and analyses of eight new USGS rock standards: U.S. Geol. Survey, Prof. Paper 840.

GOLDBERG, E.D. et al. - 1978 - Pollution history of Chesapeake Bay. Geoch. Cosmoch. Acta 42:1413-25.

GREENWOOD, R. - 1968 - "Syngenetic sulfides in sediments - Additional field evidence". Econ. Geol. 63:188-89.

HELZ, G.R. - 1976 - "Trace element inventory for northern Chesapeake Bay with emphasis on the influence of man". Geoch. Cosmoch. Acta 40:573-80.

KRAUSKOPF, K.B. - 1972 - "Introdução à Geoquímica". Polígono. vol. 2

LAMEGO, A.R. - 1945 - "A Geologia de Niterói na Tectônica da Guanabara". Rio de Janeiro, Departamento Nacional da Produção Mineral, DGM Bol. 115 .
LEE, G.F. - 1975 - "Role of hydrous metal oxides in the transport of heavy metals in the environment." In: Krenkel, P.A. (ed.), "Heavy Metals in the Aquatic Environment"., Pergamon Press, pp. 137.47.

NICHOLLS, G.D - 1971 - "Geochemical sampling problems in the analytical laboratory". Trans. Inst. Min. and Met. 80:B299-304.

NRIAGU, J.O. et al. -1979 - "Sedimentary record of heavy metal poilution in Lake Erie". Geoch. Cosmoch. Acta 43:247-58.

RICKERT, D.A. et al. - 1976 - "A synoptic survey of trace metals in botton sediments of the Willamette River, Oregon". U.S. Geol. Survey, Circular $715-\mathrm{F}$

WARD, F.N. et al. - 1963 - "Analytical methods used in Geochemical exploration by the U.S. Geological Survey". U.S. Geol. Survey, Buil. 1152. 